\title{
Analysis of pile spacing considering end-bearing soil arching and friction soil arching
}

\author{
Mingpeng Liu ${ }^{1, a}$, Hao Wang ${ }^{1, b}$, Hongbo Zhang ${ }^{1, c^{*}}$ \\ ${ }^{1}$ School of Qilu Transportation, Shandong University, Jinan, Shandong, China
}

\begin{abstract}
The soil arching effect is an important premise for anti-slide piles to exert the retaining ability. Pile space is an essential factor for the design of piles and is related to the soil arching behind piles. However, previous studies rarely considered the friction soil arching effect between piles and regarded the axis stress uniformly distributed. In this research, a method considering end-bearing soil arching and friction soil arching simultaneously was proposed to calculate the reasonable pile spacing. The said method considered the general shear failure and the yielding failure of these two soil arching. The yielding stress of inner-edge point and outer-edge point at arch-foot of the end-bearing soil arching were taken into consideration respectively. Based on the ultimate balance theory, the controlling equations of pile spacing were established. The case study showed that the method in this research conforms better to practice compared to previous researches. Matlab programming was employed to realize the automatic calculation.
\end{abstract}

\section{Introduction}

The anti-slide pile has been widely used in landslide control, excavation, and high fill subgrade for its low cost, smaller occupation, and effective retaining ability. The soil arching effect produced by pile-soil interaction is an important premise for piles to exert the retaining ability [1]. The essence of soil arching effect is the stress transformation caused by uneven movement. The soil arching could transfer the landslide thrust into the pile body and then deliver the stress to the underground. Among the influence factors of soil arching, pile space has been proven very important [2]. Too larger pile space can cause the soil arching between piles invalid and the slide of soil. While the material may be wasted if the pile space is too small. To reveal the relationship of soil arching and pile space, the soil arching effect was introduced firstly.

Soil arching effect is widespread in the field of geotechnical engineering. Terzaghi [3] firstly verified the existence of the soil arching by the trap-door test and defined it as the phenomenon of stress transformation from the yielding soil to the stationary soil. Liang and Yamin [4], Şahin [5], and Yamin [6] found that the pile space was essential to the forming of soil arching effect by analyzing the relation of soil arching and pile space. When the pile spacing becomes larger, the pile can not take advantage of the soil arching effect and becomes poor in controlling the slope sliding.

Based on the analysis of soil arching, many researchers developed the method to calculate the reasonable pile spacing. Zhou et al. [7], Jiang et al. [8], and Chen et al. [9] supposed the end-bearing soil arching undertook all the

*Corresponding author: ${ }^{\mathrm{c}}$ zhanghongbo@sdu.edu.cn

a1398404100@qq.com; b2579348445@qq.com landslide thrust and the shape of soil arching was parabolic and thus conducting the reasonable pile space according to Mohr-Coulomb strength criterion. Some researchers [1012] hypothesized the friction soil arching between piles bear all the thrust. The above studies only considered the existence of one soil arching, but Li et al. [13] pointed out the end-bearing and the friction soil arching were of the resistance to landslide together. Wu et al. [14] analyzed the condition that these two soil arching coexisted and thus conducted the estimation of pile spacing calculation. Qiu et al. [15] assumed the two soil arching shared the thrust and thus the reasonable pile space was derived. But from the mechanics principle, the friction arch does not directly undertake landslide thrust. Zhao et al. [16] divided the soil between piles into end-bearing soil arching, stabilized soil inner two arches, and the friction soil arching. The shape of two soil arching were all regarded as parabola and the pile space was thus induced according to the ultimate balance theory. But Zhang et al. [17] pointed out the shape of soil arching should not be parabolic. Considering the stationary soil behind piles, the shape of end-bearing soil arching should be ellipse. The above studies showed the consideration of pile space based on soil arching was still defective.

In this research, a method considering end-bearing soil arching and friction soil arching simultaneously was proposed to calculate the reasonable pile spacing. This method considered the general shear failure and the yielding failure of these two soil arching. The yielding stress of inner-edge point and outer-edge point at arch-foot of the end-bearing soil arching were taken into consideration respectively. Based on the ultimate balance 
theory, the controlling equations of pile spacing were established. The case study showed that the method in this research conforms better to practice compared to previous researches. Matlab programming was employed to realize the automatic calculation.

\section{Theoretical analysis}

\subsection{Basic hypothesis}

In this research, the rectangular-section pile is chosen as the basic scenario since it is widely used in supporting engineering. The other-type sections can be equivalent to rectangle section. When the difference of the length and width of pile-section is not large, the end-bearing soil arching and friction soil arching can exist simultaneously, as shown in Fig. 1. Between the end-bearing soil arching and the friction soil arching, there is a stabilized compact zone. The following hypothesis is made in this paper:

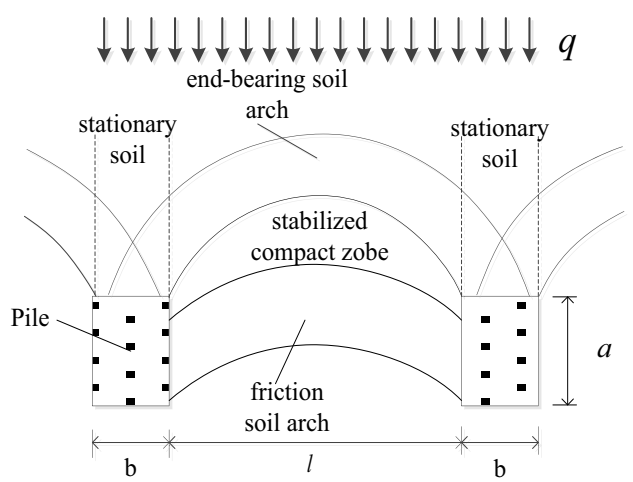

Fig. 1. Schematic diagram of soil arching effect

(1) End-bearing soil arching undertake all the landslide thrust, and friction soil arching mainly bear the load transferred from the stabilized compact zone;.

(2) The axial stress on the reasonable arch axis is the direction of the major principal stress and there is no shear stress and tensile stress perpendicular to the plane of the reasonable arch axis;

(3) The soil reaching yield state is considered the destruction of the soil.

For the stabilized compact zone, the actual force can be considered perpendicular to the axis, as shown in Fig. 2(a). The component force along $\mathrm{x}$ direction is balanced according to the symmetry. Therefore, only the force in the $\mathrm{Y}$ direction is needed to be considered, as shown in Fig. 2(b). The stress that end-bearing soil arching applied is $p_{1}$ while the stress that friction soil arching applied is $p_{2}$. It is easy to know that $p_{1}=p_{2}=p$.

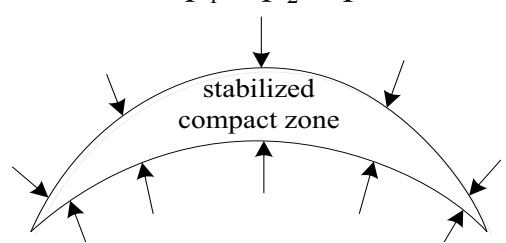

(a)

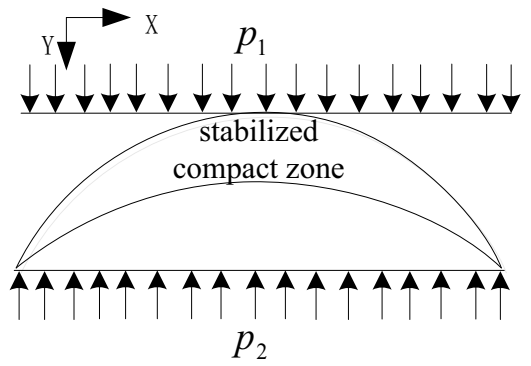

(b)

Fig. 2. The force condition of stabilized compact zone: (a) Actual force of stabilized compact zone, (b) Simplified force diagram for stable compression zone.

\subsection{Friction soil arching}

For friction soil arching, the influence of gravity is ignored. The model of soil arching can be simplified to a planestrain model. It is supposed the stress of friction soil arching is uniformly distributed on the arch. Unit piledepth is taken as the object, as shown in Fig. 3. The rise of friction $\operatorname{arch}$ is $f_{2}$. The reactive force acting on arch foot in $\mathrm{X}$ and $\mathrm{Y}$ direction are $X_{2}$ and $Y_{2}$. The reasonable arch axis is supposed as parabola [16]. The axis equation of soil arch is Eq. (1).

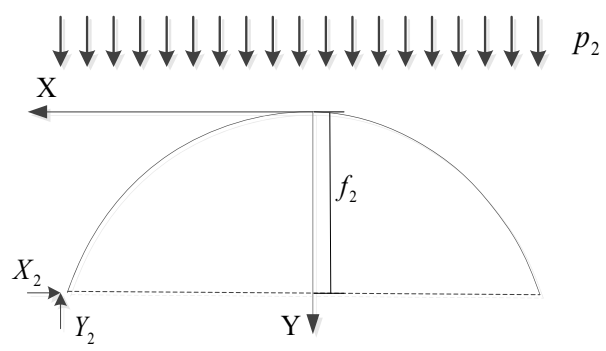

Fig. 3. Stress of friction soil arching

$y=\frac{4 f_{2} x^{2}}{l^{2}}$

From the static equilibrium of arch, Eqs. (2) can (3) be obtained:

$X_{2}=\frac{p l^{2}}{8 f_{2}}$

$Y_{2}=\frac{p l}{2}$

For the friction, the failure at arch-foot is considered controlling condition. The worst interface is pile-soil interface, thus the pile-soil interface is considered the slide face, as shown in Fig. 4. According to the force balance in the slide face, Eq. (4) can be listed:

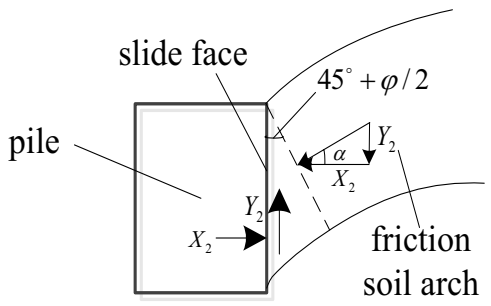

Fig. 4. Stress condition of Arch-foot of friction soil arch 


$$
X_{2} \tan \delta+c a=Y_{2}
$$

Where $\delta$ is the friction angle of pile-soil interface. Substituting Eqs. (2) and (3) into Eq. (4) induces Eq. (5):

$$
\frac{p l^{2}}{8 f_{2}} \tan \delta+c a=\frac{p l}{2}
$$

According to the ultimate balance theory, the angle of the slide surface of soil arch and the major principal stress plane should be $45^{\circ}+\varphi / 2$. From Fig. 4 , Eq. (6) can be obtained:

$$
\tan \alpha=\frac{Y_{2}}{X_{2}}=\frac{4 f_{2}}{l}=\tan \left(45^{\circ}+\frac{\delta}{2}\right)
$$

Therefore, Eq. (7) can be conducted by combining Eqs. (5) and (6):

$$
p=\frac{2 c a}{l\left[1-\tan \left(45^{\circ}-\delta / 2\right) \tan \delta\right]}
$$

\subsection{End-bearing soil arching}

For the end-bearing soil arching, it should undertake all the landslide thrust and is subjected to reaction force of stabilized compact zone. According to Terzaghi soil arching principle, the stationary soil behind piles can produce a lateral pressure to end-bearing soil arch. The stress diagram of end-bearing soil arching is shown in Fig. 5. The landslide thrust is noted as $q$, and the lateral pressure is $K_{0} q$. Where $K_{0}$ is the static earth pressure coefficient and can be estimated by $K_{0} \approx 1-\sin \varphi$.

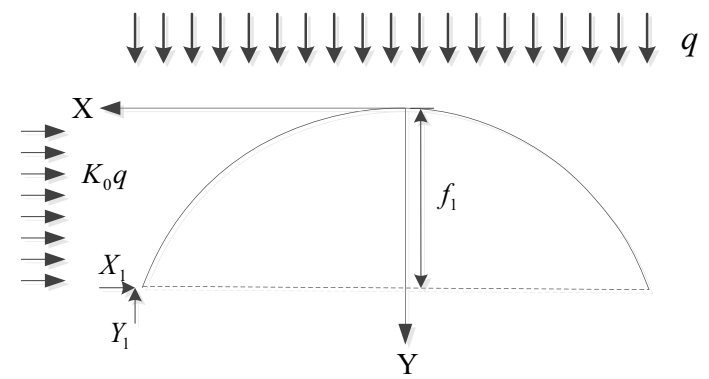

Fig. 5. Stress diagram of end-bearing soil arching

The reactive force acting on arch foot in $\mathrm{X}$ and $\mathrm{Y}$ direction are $X_{1}$ and $Y_{2}$, respectively. The axis equation of end-bearing is Eq. (8) when subjected to lateral pressure [17].

$\frac{x^{2}}{\left(B \sqrt{K_{0}}\right)^{2}}+\frac{(y-B)^{2}}{B^{2}}=1$

Where,

$B=\frac{f_{1}}{2}+\frac{l^{2}}{8 f_{1} K_{0}}$

For the end-bearing soil arch, the failure at arch-foot is also considered controlling condition. The angle between axis at the arch foot and horizontal direction is noted as $\theta$. As a result, $\tan \theta$ and the axis force $F_{N}$ at the arch foot can be listed as follows:

$Y_{1}=\frac{q l}{2}$

$$
\begin{aligned}
& \tan \theta=\left.\frac{d y}{d x}\right|_{x=\frac{l}{2}, y=f_{1}}=-\left.\frac{x}{K_{0}(y-B)}\right|_{x=\frac{l}{2}, y=f_{1}}=\frac{4 f_{1} l}{l^{2}-4 K_{0} f_{1}^{2}} \\
& \left.F_{N}\right|_{x=\frac{l}{2}}=\frac{Y_{1}}{\sin \theta}=\frac{q l}{2} \sqrt{1+\left[\frac{l^{2}-4 K_{0} f_{1}^{2}}{4 f_{1} l}\right]^{2}}
\end{aligned}
$$

For the end-bearing soil arching, the soil in the zone of soil arching reaches yielding state everywhere. The inneredge point and the outer-edge point of arch foot is marked as $\mathrm{A}$ and $\mathrm{B}$. And their corresponding axis stress is $\sigma_{A}$ and $\sigma_{B}$ respectively. To be convenient to calculate, the distribution of the axis stress from point $A$ to $B$ is assumed linear along the thickness of arch $t$, as shown in Fig. 6(a).

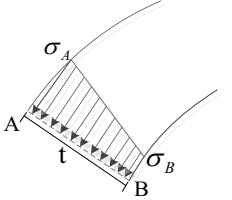

(a)

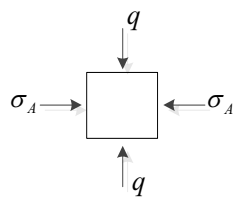

(b)

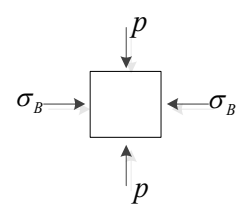

(c)
Fig. 6. The stress condition of soil arch foot: (a) Distribution of axial stress, (b) Stress state of A (c) stress state of B.

For point $\mathrm{A}$, the landslide thrust is the major reason accounting to its yielding. Its minor principal stress is landslide stress $q$ and the major principal stress is arch axis stress $\sigma_{A}$. The stress state of $\mathrm{A}$ is shown as Fig. 6(b). According to the Mohr-Coulomb yield criterion, Eq. (13) can be acquired:

$\sigma_{A}=q \tan ^{2}\left(45^{\circ}+\varphi / 2\right)+2 c \tan \left(45^{\circ}+\varphi / 2\right)$

For point $\mathrm{B}$, the axis stress is the major principal stress and reaction stress of stabilized compact zone $p$ is minor principal stress, as shown in Fig. 6(c).

$$
\sigma_{B}=p \tan ^{2}\left(45^{\circ}+\varphi / 2\right)+2 c \tan \left(45^{\circ}+\varphi / 2\right)
$$

The axial force can be regarded as the integral of axial stress along soil arch thickness. Thus, Eq. (15) can be listed:

$$
\frac{\sigma_{A}+\sigma_{B}}{2} t=\sigma_{N} t=F_{N}
$$

Where, $\sigma_{N}$ is the mean axis stress and is expressed as:

$$
\sigma_{N}=\left(\sigma_{A}+\sigma_{B}\right) / 2
$$

Then it is assumed the thickness of arch $t$ to be equal to pile width, $t=b$. Substituting Eqs. (13), (14) and (15) into Eq. (12) can obtain Eq. (17):

$$
f_{1}=\frac{l}{2 K_{0}}\left\{\left[-\sqrt{\left(\frac{2 \sigma_{N} b}{q l}\right)^{2}-1}\right]+\sqrt{\left(\frac{2 \sigma_{N} b}{q l}\right)^{2}-1+K_{0}}\right\}
$$

Eq. (16) expresses the arch rise of end-bearing soil arching. For a special condition, the arch rise is related to the landslide thrust and pile space. This conclusion conforms engineer experience. The failure of end-bearing soil arch is then taken into consideration. According to ultimate balance theory, the angle of the slide surface of soil arch and the major principal stress plane should be $45^{\circ}+\varphi / 2$. The stable compression zone behind piles is assumed to be a keystone area, as shown in Fig. 7. Based on the force balance in the slide face, Eq. (18) can be acquired: 


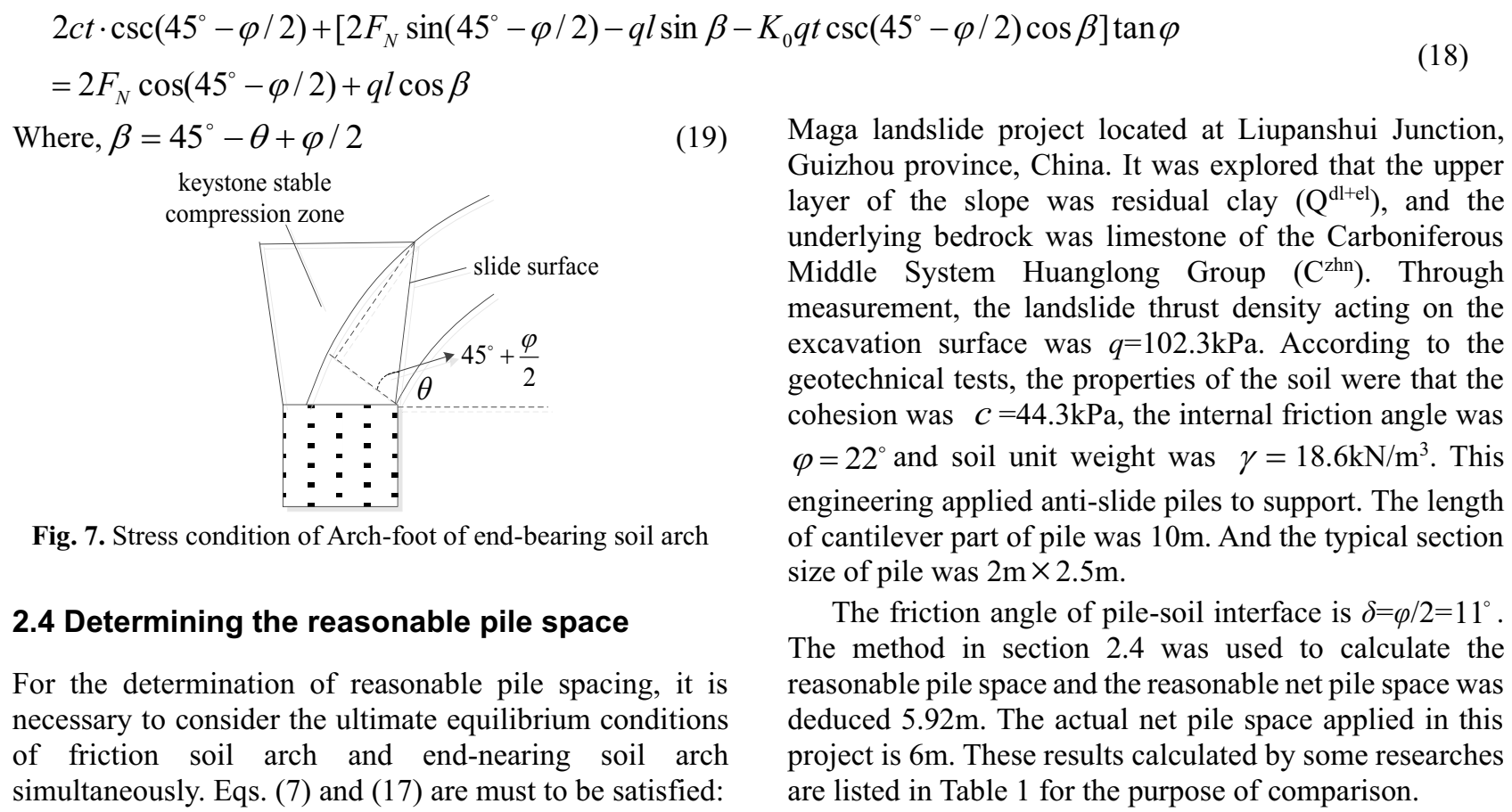

$$
\left\{\begin{array}{l}
2 c t \cdot \csc \left(45^{\circ}-\varphi / 2\right)+\left[2 F_{N} \sin \left(45^{\circ}-\varphi / 2\right)-q l \sin \beta-K_{0} q t \csc \left(45^{\circ}-\varphi / 2\right) \cos \beta\right] \tan \varphi \\
=2 F_{N} \cos \left(45^{\circ}-\varphi / 2\right)+q l \cos \beta \\
F_{N}=\frac{b}{2}\left[\left(q+p_{2}\right) \tan ^{2}\left(45^{\circ}+\varphi / 2\right)+4 c \tan \left(45^{\circ}+\varphi / 2\right)\right] \\
p=\frac{2 c a}{l\left[1-\tan \left(45^{\circ}-\delta / 2\right) \tan \delta\right]}
\end{array}\right.
$$

The pile spacing that satisfies the Eq. (19) can simultaneously satisfy the static equilibrium of friction soil arch and end-bearing soil arch in the limit state. Thus, the pile space solved by Eq. (19) is just the reasonable pile space. Eq. (19) is the implicit function of $l$ which is difficult to be obtained directly. Therefore, Matlab programming is employed to obtain the numerical solution of $l$. For Eq. (18), the left side of the equal sign can be regarded as the anti-slip force on the slip surface, and the right side is the sliding force on the slip surface. Supposing the following Eq. (20) to analyze:
From Table 1, since the assumption conditions were different, the value of net pile space varied significantly among different studies. Reference [7-9, 10] only considered one type soil arching. Reference [14-16] considered the combined effect of these two soil arching. But reference [14-15] assumed the friction can bear landslide thrust, thus the result were larger. Reference [16] did not considering the yielding condition of soil arching, the result was also a little larger for engineering design. The result of this research conforms better to practice.

$$
\begin{aligned}
& F=2 c t \cdot \csc \left(45^{\circ}-\varphi / 2\right)+\left[2 F_{N} \sin \left(45^{\circ}-\varphi / 2\right)-q l \sin \beta-K_{0} q t \csc \left(45^{\circ}-\varphi / 2\right) \cos \beta\right] \tan \varphi \\
& -2 F_{N} \cos \left(45^{\circ}-\varphi / 2\right)+q l \cos \beta
\end{aligned}
$$$$
F_{N} \text { and } p \text { can be regarded as parameters. And the }
$$
reasonable pile spacing is transferred into the minimal $l$ when $F \geq 0$. The numerical method is as following: given a smaller initial $l_{1}$ and substitute $l_{1}$ into Eq. (20). If $F<0$, iterating $l_{i}=l_{1}+\Delta l$, then substitute $l_{i}$ into Eq. (20) until $l_{i}$ satisfies $F \geq 0$. Then, output $l_{i}$, and the reasonable pile spacing can be expressed as following: $L=b+l_{i}$

\section{Results \& Discussion}

\subsection{Case study}

Table 1. Comparison of calculation result of pile space

\begin{tabular}{|c|c|}
\hline Reference & clear pile space $l(\mathrm{~m})$ \\
\hline Chen et al. [9] & 3.56 \\
\hline Jiang et al. [8] & 3.84 \\
\hline
\end{tabular}




\begin{tabular}{|c|c|}
\hline Zhou et al. [7] & 3.20 \\
\hline Wang et al. [10] & 8.73 \\
\hline Zhao et al, [16] & 6.35 \\
\hline Wu et al. [14] & 6.15 \\
\hline Qiu et al. [15] & 9.25 \\
\hline This research & 5.92 \\
\hline
\end{tabular}

\subsection{Parameters analysis}

From the Eq. (19), the reasonable net pile space is related to soil properties (cohesion $c$; inter friction angle $\varphi$ ) and design parameters (pile width $b$, length of pile section $a$ ). To investigate the influence of various parameters on the pile space, the case in section 3.1 is still selected for parameter analysis.

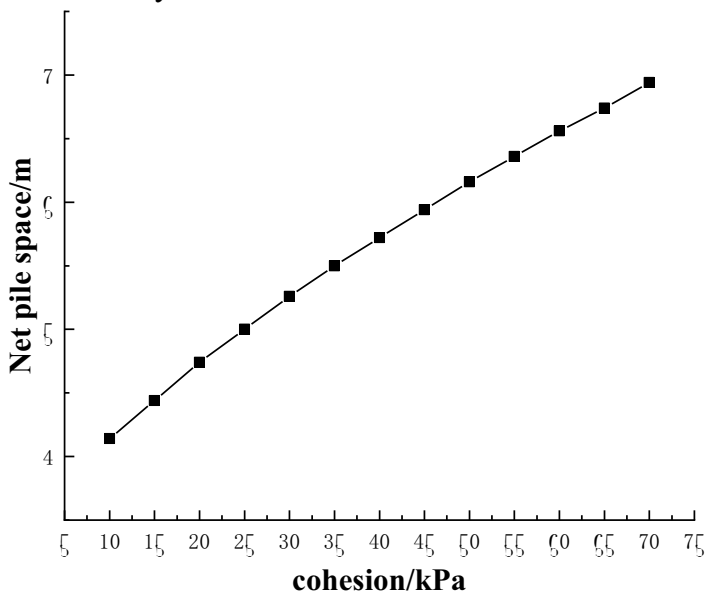

(a)

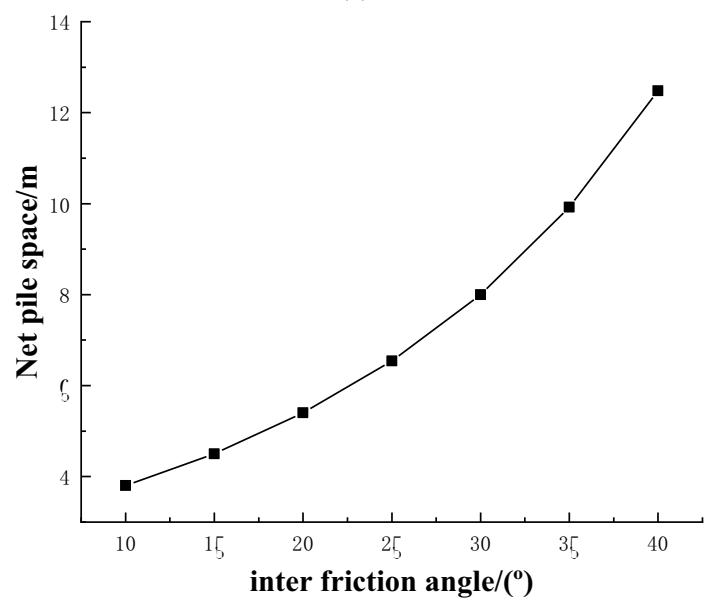

(b)

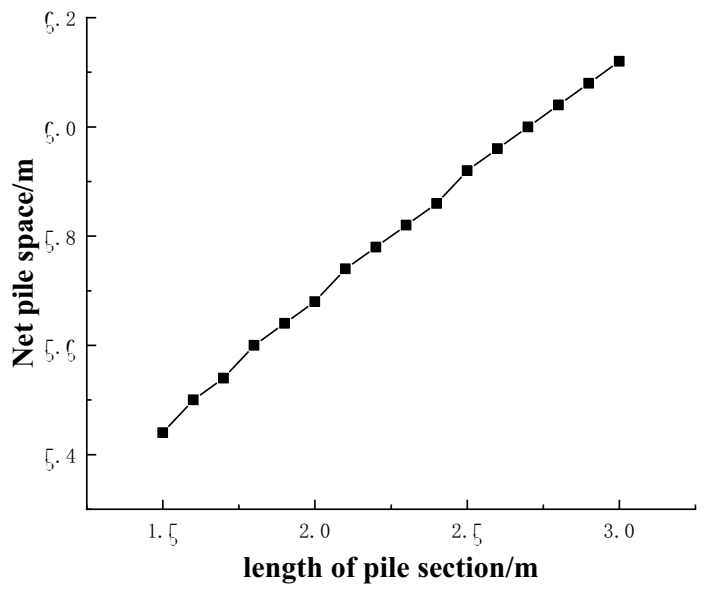

(c)

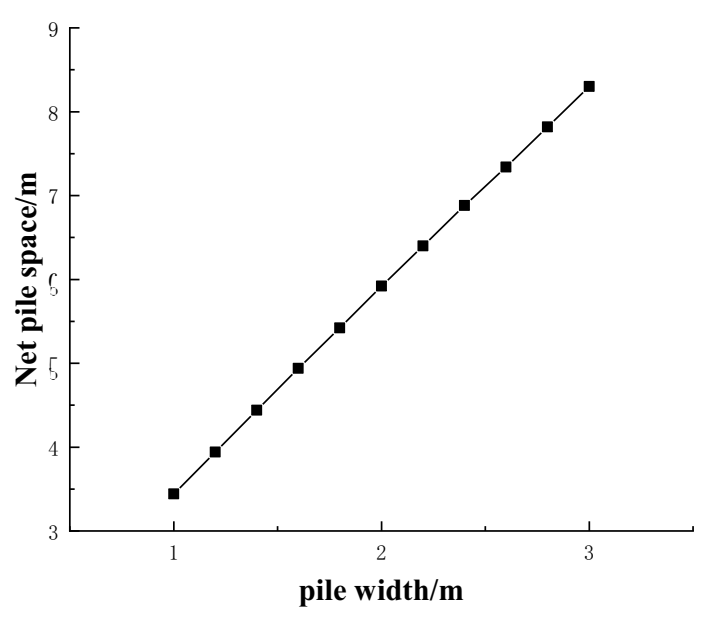

(d)

Fig. 8. Relation of pile space and parameters: (a) Influence of cohesion, (b) Influence of inter friction angle, (c) Influence of length of pile section, (d) Influence of pile width.

Fig. 8 shows the relation of pile space and parameters. As can be seen in Figs. 8(a) and 8(b), the net pile space increased with the increasing $c$ and $\varphi$. But the increasing rate of $\varphi$ is more higher. This variation presented that the internal friction angle has a greater influence. The higher soil property corresponded to larger pile space.

Figs. 8(c) and 8(d) reflect the influence of a and b. With the increasing pile width and length of pile section, pile spacing presented linear increasing. But pile space was more sensitive. This is because the end-bearing soil arching dominated in the two soil arching.

\subsection{Ultimate bearing capacity of two soil arching}

This research assumes the end-bearing to undertake all the landslide thrust and the friction soil arching bear the stress from the stabilized compact zone. This section studied the ultimate bearing capacity of two soil arch. For friction soil arching, its ultimate bearing capacity can be determined by Eq. (7).

$p=\frac{2 c a}{l\left[1-\tan \left(45^{\circ}-\delta / 2\right) \tan \delta\right]}$

For the end-bearing soil arching, the soil arching effect is generated by the landslide thrust. The exertion of soil arching effect can be considered as the existence of arch 
rise. That corresponds to Eq. (17) has a solution:

$$
\left(\frac{2 \sigma_{N} b}{q l}\right)^{2}-1 \geq 0
$$

Substituting Eqs. (13), (14) and (16) into Eq. (21) induces:

$$
q \leq \frac{b\left[p \tan ^{2}\left(45^{\circ}+\varphi / 2\right)+4 c \tan \left(45^{\circ}+\varphi / 2\right)\right]}{l-b \tan ^{2}\left(45^{\circ}+\varphi / 2\right)}
$$

When the equal sign is taken, the result calculated from Eq. (22) is the maximal landslide thrust that end-bearing soil arching can bear. Thus, the ratio of ultimate bearing capacity of two soil arch can be listed as following:

$$
n=\frac{q}{p}
$$

By calculation, the value of $n$ in the case is 10.8 . This result illustrate that ultimate bearing capacity of friction soil arching is about $1 / 10$ of the end-bearing soil arching. And the maximal landslide thrust of this design is $468.9 \mathrm{kPa}$. Eq. (22) can also be used to judge whether the design condition could satisfy the requirement of landslide thrust.

\section{Conclusion}

According to the ultimate balance condition when two soil arching exerted together, the method to calculate reasonable pile space was induced. Main conclusions were listed as following:

(1) The soil between piles could be divided into three parts. The inner-edge point and outer-edge point of endbearing soil arch needed to satisfy M-C yield criterion. Friction soil arching bore the stress from the stabilized compact zone.

(2) The reasonable pile space was determined by the static equilibrium of the slide face and condition that the axis stress reached yielding stress.

(3) Among the influence factors of pile spacing, inter friction angle of soil and pile width were more important.

(4) The ultimate bearing capacity of two soil arching and the maximal landslide that this model can undertake were analyzed. Result showed

\section{Acknowledgments}

This paper was supported in part by the Key Research and Development Program of Shandong Province (NO. 2019GSF109045).

\section{Reference}

1. Keawsawasvong S, Ukritchon B. (2017) Undrained limiting pressure behind soil gaps in contiguous pile walls. Computers and Geotechnics, 83, 2017, pp. 152-158.

2. Li C, Tang H, Hu X, et al. (2013) Numerical modelling study of the load sharing law of antisliding piles based on the soil arching effect for
Erliban landslide, China. KSCE Journal of Civil Engineering 17(6): 1251-1262.

3. Terzaghi K. (1936) Stress distribution in dry and in saturated sand above a yielding trap-door. Proc. 1st Int. Conf. Soil Mech., Harvard University, Cambridge, Mass., 1, 307-311.

4. Liang RY, Yamin M. (2010) Three-dimensional finite element study of arching behavior in slope drilled shafts system. International Journal for Numerical and Analytical Methods in Geomechanics 34(11), 1157-1168

5. Şahin, A. (2011). Mathematical models and solution algorithms for computational design of RC piles under structural effects. Applied Mathematical Modeling 35(7), 3611-3638.

6. Yamin M. (2007). Landslide stabilization using a single row of rock-socketed drilled shafts and analysis of laterally loaded drilled shafts using shaft deflection data. PhD Thesis, The University of Akron, Akron, USA.

7. Zhou DP, Xiao SG, Xia X. (2004) Discussion on rational spacing between adjacent anti-slide piles in some cutting slope projects[J]. Chinese Joural of Geotechinal, 26(1): 132-135.

8. Jiang LW, Huang RQ, Jiang ZX. (2006) Analysis of soil arching effect between adjacent piles and their spacing in cohesive soils. Rock and Soil Mechanics, 27(3): 445-450.

9. Chen G, Zou L, Wang Q, et al. (2020) Pile-Spacing Calculation of Anti-Slide Pile Based on Soil Arching Effect. Advances in Civil Engineering, 2020(6269):1-6.

10. Wang CH, Chen YB, Lin LX. (2001) Soil arch mechanical character and suitable space between one another anti-sliding pile. Journal of Mountain science, 19(6): 556-559.

11. Zhao MH, Liao BB, Liu SS. (2010) Calculation of anti-slide piles spacing based on soil arching effect. Rock and Soil Mechanics, 31(4): 1211-1216.

12. Deng XH, Jian WX. (2014) Study on model calculating spacing of anti-slide piles based on friction arch. Subgrade Engineering, 3: 31-36.

13. Li C, Tang H, Hu X, et al. (2013) Numerical modelling study of the load sharing law of antisliding piles based on the soil arching effect for Erliban landslide, China. KSCE Journal of Civil Engineering, 17(6):1251-1262.

14. Wu J, Li C, Liu Q, et al. (2017) Optimal isosceles trapezoid cross section of laterally loaded piles based on friction soil arching. KSCE Journal of Civil Engineering 21(7):2655-2664.

15. Qiu ZY, Han TC, Dou HQ. (2016) Analysis of spacing between anti-slide piles considering soil arch on lateral sides and back. Journal of Zhejiang University (Engineering Science) 50(3):559-565.

16. Zhao MH, Peng WZ, Yang CW, et al. (2019) Study on Spacing of Anti-slide Piles Considering Combined Soil Arching Effect on Lateral Side and 
Back. Journal of Highway and Transportation Research and Development, 36(3):87-94.

17. Zhang H, Chen J, Ma H, et al. (2019) A New Method to Determine a Reasonable Pile Spacing of Stabilizing Piles and Earth Pressure on Sheet Piles. Journal of Engineering Science \& Technology Review, 12(1):37-44. 